\title{
Teoría literaria latinoamericana en Argentina. Lecturas, debates, ¿crisis?
}

\author{
SILVANA FLORENCIA SANTUCCI Universidad Autónoma de Entre Ríos - Universidad Nacional del Litoral - \\ CONICET, Argentina / silvanasantucci@gmail.com
}

\section{Resumen}

Instamos a algunos profesores argentinos de diversas generaciones y universidades a escribir sobre la existencia de una Teoría Literaria Latinoamericana. Quienes integran el número se sumaron a sostener, definir, cuestionar, actualizar, historizar y documentar distintos aspectos de la ficción de objeto que le interesa a nuestra investigación posdoctoral. Una ficción que, marcadamente política y a la vez pretenciosa, contempla el abordaje teórico de su propia tópica generalizadora: América Latina, trazando una serie de sentidos que excede las tramas cristalizadas por las miradas nacionales de los fenómenos literarios.

Palabras clave: Teoría literaria latinoamericana / Argentina / debates / lecturas

\section{Latin American Literary Theory in Argentina. Readings, discussions, crisis? \\ Abstract}

We urge some argentinean professors of different generations and at various universities to write about the existence of a Latin American Literary Theory. Those who write in this issue joined in to sustain, define, question, update, historicize, and document different aspects of the object fiction that is the interest of our post-doctoral research. A fiction that, markedly political and at the same time pretentious, contemplates the theoretical approach of its own generalizing topic: Latin America constructed in a totalizing fashion, but that in its constituent impossibility allows the discovery of particularities that exert a plus in meaning that exceeds the frames crystallized by the national views of literary phenomena.

Key words: Latin American Literary Theory / Argentina / readings / discussions

Recibido: 16/10/2018. Aceptado: 20/10/2018

Para citar este artículo: Santucci, Silvana (2018). Teoría literaria latinoamericana en Argentina. Lecturas, debates, ¿crisis? El taco en la brea, 8 (junio-noviembre), 54-58. Santa Fe, Argentina: UNL. DOI: 10.14409/ tb.v1i8.7755 
¡Oh, cuerpo mío, haz de mí, siempre, un hombre [una mujer] que interrogue!

Frantz Fanon

Con el objeto de someter a discusión alguna de las hipótesis centrales de la investigación posdoctoral que llevamos adelante, titulada: «La teoría literaria latinoamericana en las aulas de la universidad argentina de la posdictadura. Formaciones, deslindes y desplazamientos (1984-1989)» instamos a algunos profesores argentinos, de diversas generaciones y universidades, a escribir sobre la existencia de una Teoría Literaria Latinoamericana', si es que pudiese distinguirse un objeto semejante, de entre los modos propiciados por el hacer crítico local en su trabajo con los textos literarios.

Puedo decir, con cierto orgullo, que quienes integran el número se sumaron a sostener, definir, cuestionar, actualizar, historizar y documentar distintos aspectos de la ficción de objeto que le interesa a nuestra investigación. Una ficción que, marcadamente política y a la vez pretenciosa, contempla el abordaje teórico de su propia tópica generalizadora: América Latina; construida con rasgo totalizador, pero que en su imposibilidad constitutiva (y también contradictoria) permite el descubrimiento de particularidades que ejercen un plus de sentido que excede las tramas cristalizadas por las miradas nacionales de los fenómenos literarios.

De esta manera, Raúl Antelo, propone que la literatura «sobre todo la latinoamericana, en Argentina pero también en todas partes» exige ser leída en su propia inteligibilidad, desde una «reserva de imaginación» que desactive la inercia de la historia y, a partir de la cual, se vuelva posible organizar nuevos modos de soberanía: la venganza contra-histórica que promueve y practica sería una de ellas.

En esta misma perspectiva, Miguel Dalmaroni ensaya tres hipótesis en las que desenlaza o separa el supuesto de que características locales permitirían entender la relación «estrecha y duradera» (un matrimonio más que conflictivo a esta altura) entre la crítica literaria argentina y la teoría. Esto permite entenderla como un fenómeno global en el que la denominación de «teoría» conserva un utilitarismo que nos permite continuar nombrando a aquellas escrituras «que se efectúan por ese impulso, ese ímpetu, ese deseo» relativo al saber y a sus políticas; resalta el uso del término deseo propuesto por Jonathan Culler. Habría en conclusión teoría cuando hay deseo de pensamiento, categorías en uso para hacer sentido, imaginación reservada para escribir sobre la literatura de nuestra y de todas las partes del mapa.

Ignacio Iriarte, por su parte, prueba la hipótesis de la existencia de una «ética» de la teoría literaria en algunos ejemplos argentinos y en un caso cubano. Compara a esta posición con la organizada por Lacan para La ética del psicoanálisis cuando pregunta: «¿Ha actuado usted en conformidad con el deseo que lo habita?». Esta ética de la teoría, entonces, no consistiría en volver a los instintos primordiales, sino en «abandonar los objetos en los que el individuo se ha enredado para descubrir la pureza del deseo que lo sostiene». Un deseo que, como bien estabiliza la propia teoría literaria, apunta a un objeto que se define por desaparecer. A la vez, el foco de nuestro trabajo no apunta específicamente a la institucionalización de un objeto como el que propone Diego Peller: una Teoría Literaria en argentina «con perspectiva latinoamericana». Por el contrario, recuperamos la apuesta o sostenemos el deseo (categoría que su trabajo también reinstala, pero para usarla lateralmente y con cierto desprecio por los usos encubridores que habilitaría) de una línea teórica, acaso imaginaria, que revista a la producción crítica e intelectual argentina con valores por fuera de los que supieron construir las tramas culturales que organizaron las miradas exógenas y 
definitorias de su propia configuración identitaria. Nos referimos a la inmigración europea y por consiguiente, a la criollización de la patria, en este caso, intelectual. ${ }^{2}$

$\mathrm{Si}$ a algo queremos aludir con Teoría literaria latinoamericana en Argentina no es al «río de sueñera y de barro» con el que poéticamente las proas fundaron míticamente la literatura del Río de la Plata, sino al pensamiento sobre los sectores históricamente excluidos, que las críticas criollas o plebeyas, como las de Sarlo, Perlongher o Link por nombrar algunas, han dado lugar. Hablamos de ciertas reivindicaciones teóricas de larga tradición en la literatura del continente americano, con voces propias, pero que, en la escena local no han adquirido una potencia reivindicativa semejante, proveniente de sus propios sectores, sino hasta finales de siglo XX e inicios del XXI. Tal vez esa ausencia provenga, en parte, de que hablamos de cuerpos que interrogan tal como propone el epígrafe desde una lógica que los hizo visibles sólo a rasgo y que, por lo tanto, refractan (como la propia noción de América Latina en Argentina, cuya conciencia cohesiva es siempre discutible) una función históricamente débil de su homogeneización, la cual resulta imposible de habitar como ficción totalizante a lo largo del siglo XX. Frantz Fanon en Piel refiere a estas marcas: el lugar siempre exteriorizante con el que accedimos a los discursos indigenistas y de la negritud.

$\mathrm{Al}$ respecto, el artículo de Mónica Bernabé dedicado a la imagen en el tecnoindigenismo de Chambi y sus trabajos en relación con «el contrapunteo cubano» como categoría bifronte pero avant-garde, entre los estudios culturales y los latinoamericanos, constituye una línea de desarrollos clave para el relevo de estas cuestiones en la argentina, así como el trabajo de Leonel Cherri con la integración de Brasil a la imagen «novomundana» de América Latina. Sus discusiones acerca de la política de uso de la denominación del continente y el lugar de la antropofagia modernista como estructura teórica delimitan lo que entendemos (y celebramos) como un nuevo régimen escópico para las artes latinoamericanas en el Río de la Plata.

Por otra parte, la tesis principal bajo la cual convocamos a estos profesores, postula que: en la universidad argentina, la enseñanza de la literatura latinoamericana propició el surgimiento de una «teoría literaria latinoamericana» que definió su formación en la posdictadura (Feierstein, Antelo, Feld y Franco, Gerbaudo, Schwarzböck). A la vez, el archivo de la misma determina un estado de la «imaginación americana» que es necesario explorar.

Sin embargo, la denominación de «latinoamericana» para impartir la enseñanza de un conjunto de textos en lengua española, pertenecientes a escritores de países fundamentalmente caribeños y sudamericanos fue utilizada por primera vez en la Universidad de Buenos Aires (UBA) durante casi todo 1973 por Noé Jitrik y su, por entonces, Jefa de Trabajos Prácticos, Josefina Ludmer (a diferencia de la Universidad de Tucumán que lo hizo desde inicios de 1970).

Este período, el de la "primavera camporista», que se conoce como la universidad «del mito» (Puiggrós:75), momento en que la UBA adoptó el nombre de Universidad Nacional y Popular de Buenos Aires, puso en marcha una reforma pedagógica que, si bien «no tuvo un carácter espectacular», «ni había nacido por generación espontánea», constituyó la expresión «más actualizada de propuestas y experiencias reformistas incluso de sectores humanistas avanzados» (Puiggrós:76-77). Esta reforma pedagógica trazó un correlato con los movimientos teóricos producidos en el campo de la literatura latinoamericana y si bien, durante la dictadura este movimiento se interrumpió, nuestra hipótesis asume que algunos de aquellos lineamientos fueron retomados desde otras claves en los primeros años de la posdictadura.

En este marco, Diego Peller discute algunas de las configuraciones políticas que sostienen esa 
lectura histórica de la institucionalización de la Teoría Literaria en Argentina y sobretodo, suspende el juicio por el cual la dictadura debiera asumirse como un agente interruptor de la consolidación de una "teoría» en el país. Si bien no romantiza la experiencia de formación en las catacumbas, discute cómo pese a la fuerte discontinuidad que supuso la dictadura, el momento de refundación de la carrera de Letras de la UBA en los años 1984-1985 comportó un altísimo grado de sofisticación teórica. Y con gran voluntad polémica se interroga: «¿No podría deducirse (...) que los grupos de estudio privados durante la dictadura no constituyeron una "restricción" para el desarrollo de la Teoría sino su ámbito más propicio de florecimiento, quizás porque la dictadura, como estado de excepción permanente y caracterizado por un despliegue inusitado de represión y violencia puede haber alentado, entre los que sostenían el ejercicio de la práctica teórica, la convicción de que defender ese espacio, contra todo y contra todos, era un asunto de la mayor relevancia? ¿No habrá dotado la dictadura al ejercicio de la Teoría de un aura épica de lucha y resistencia ideológico-política que quizás se disolvió paulatinamente en la "normalización" del tiempo histórico posterior?». La disputa por los sentidos políticos de la teoría en la agenda institucionalizadora del pensamiento sobre la literatura definen los tobillos de las prácticas a los que apuntan los interrogantes de Peller. Y especialmente cuestiona el lugar del estructuralismo en esa agenda de enseñanza.

Por otro lado, recuperamos las voces de dos de los profesores destacados y protagonistas del proceso histórico de formulación del objeto que nos convoca.

En primer lugar, en la sección Archivos, exhumamos un trabajo Noe Jitrik publicado en México, en 1986. El mismo expone una preocupación teórica central que le permitió definir aspectos básicos para la configuración de su campo trabajo: qué tensiones de la «literatura latinoamericana» eran claves para leer su "proceso constituyente», es decir, aquello que aquí leemos, en términos de Candido (1959) como su «formación». Jitrik organiza su enfoque tomando en cuenta dos perspectivas, una mirada centrada en la «historia literaria» y otra anclada en lo que define como la «crítica». Por un lado, asume que el surgimiento de la literatura de América Latina responde a una construcción lógica y necesaria y, por el otro, a través de la acumulación de elementos concurrentes, de carácter explicativo, lee en ellos la base para que dicha construcción acontezca. La escritura trabaja reponiendo imágenes y escenas, a las que define como «rasgos de origen» y las llama «intuiciones» y «esbozos». Las mismas le permiten elaborar una idea aproximada de la configuración del proceso, desde una mirada que define como «argentina». Por otra parte, la expresión América Latina es asumida desde un carácter «provisorio, sobre el que se arriesgan «interpretaciones».

Asimismo, la brevísima experiencia realizada en 1973 en las entonces denominadas «cátedras nacionales» es recuperada por Celina Manzoni en un texto de antología, que deja abierto el deseo de volver sobre su archivo: aquellos materiales de clases y documentos que afirman la potencia teórica del período. Manzoni reflexiona sobre su experiencia docente en la cátedra dirigida por Noé Jitrik en 1973, donde participó como auxiliar y compartió «la voluntad de renovación e incluso el fervor que caracterizó el momento». Según su relato, venía de asistir a los cursos privados de teoría literaria que dictaba Jitrik y de donde surgieron algunos de los invitados a formar parte de la cátedra. "A los textos mayores del estructuralismo y las polémicas que los rodearon, bastante transitadas entonces, se sumaron algunos autores de lo que sería llamado posestructuralismo. La cátedra de Literatura Iberoamericana se organizaba en torno a tres campos (crítico, teórico y contextual) que, más o menos coordinados, dictaban los tres profesores (Jitrik, Ludmer, Ruffinelli) 
en las respectivas clases teóricas: un ingreso a los textos desde enfoques diversos y eventualmente complementarios que se ponían en discusión en los prácticos. Una experiencia intensa quebrada por la prepotencia de una historia que corresponde recuperar no solo desde las memorias, sino desde la materialidad de la letra de los programas, de la bibliografía y de las metodologías enseñadas». Manzoni pone en valor el archivo de la imaginación teórica latinoamericana que nos interesa, puesto que el pasado ficcional de América Latina (ese que nos trajo hasta aquí, producto de la episteme conquistadora, expoliadora e institucionalizadora del capital) nos sigue arrojando preguntas para el sostenimiento de un pensamiento (deseoso de) por venir. América Latina continúa frente al desafío, la exageración mítica, trascendental, inmanente y barroca, de reorganizarse nuevamente ante su propia imagen, esta vez, encantadora (como Quetzalcóatl de regreso, luego del estadio gemelar del espejo). Interrogarnos, todavía, por la especificidad de una teoría que, aunque global, no termina de particularizarse resulta un contrasentido problemáticamente incómodo pero certeramente nuestro.

\section{Notas}

1 cf. Reyes, Rodó, Cornejo Polar, Rama, Lezama Lima, Sarduy, 2 Analía Gerbaudo en uno de sus trabajos sobre la internaCándido, Ludmer, Antelo, Pizarro, Zanetti, Ramos, Santiago, Fernández Retamar, Link, Perilli, Manzoni, Sosnowski. cionalización de la figura de Beatriz Sarlo va a reivindicar el carácter de «intelectual criollita» con que ella se describe y describe a su propia producción intelectual.

\section{Referencias bibliográficas}

Bernabé, M. (2017). Contrapunteo de la cultura de las humanidades y los estudios de la cultura. Revista Cuadernos de Literatura. Pontífica Universidad Javierana, 21(14).

http://revistas.javeriana.edu.co/index.php/cualit/article/view/19370

Gerbaudo, A. (2017). Fantasías pedagógicas: Beatriz Sarlo y sus traducciones para Punto de vista (1978-1984). Revista Historia de la Traducción. http://www.traduccionliteraria.org/1611/art/gerbaudo.htm

Fanon, F. (2009). Piel Negra, máscaras blancas. Madrid: Akal.

Puiggros, A. (1987). La universidad del Mito. En Discusiones entre educación y política. Buenos Aires: Galerna, $87-118$. 